\title{
A CUMULATIVE PROSPECT THEORY APPROACH TO CAR OWNER MODE CHOICE BEHAVIOUR PREDICTION
}

\author{
Shi An, Xiaowei Hu, Jian Wang \\ School of Transportation Science and Engineering, Harbin Institute of Technology, Harbin, China
}

Submitted 25 April 2012; resubmitted 27 August 2012, 19 November 2012; accepted 31 December 2012

\begin{abstract}
The uncertain transportation environment makes travel's mode choice decision-making behaviour become a complex and alterable process. Based on the cumulative prospect theory, this paper analysed the long-standing use of utility theory for the travel's mode choice behaviour research. Car owner's generalized cost includes the transport fare, travel time cost and penalty cost (early or delay); cumulative prospect theory was applied to describe the uncertain and risky prospect of car owner under congestion pricing policy. Through analysing two kinds of car owner's generalized subjective perception costs on the four different transportation modes, including bus, subway, taxi and private car; we calculated the mode choice's prospect value before and after the implementation of congestion pricing, and compared the difference of numerical example between cumulative prospect theory and expected utility theory. The results indicated that after the implementation of congestion pricing policy, the middle-level income car owner would prefer to choose taxi. Based on a state preference survey on travel's mode choice behaviour, the survey results further validated our analysis. This paper for the first time adopted cumulative prospect theory to analyse travel's mode choice behaviour after the implementation of congestion pricing policy, which can better explain car owner's mode choice decisionmaking process under uncertain and risk condition. This study also can be helpful to many cities that wish to establish and implement the congestion pricing policy in practice.
\end{abstract}

Keywords: travel behaviour; cumulative prospect theory; utility theory; mode choice; congestion pricing; stated preference survey.

\section{Introduction}

Most of road traffic congestions can be attributed to irrational pricing which sets the mode's price much lower than its actual cost in urban transportation service. Especially in the payment of motor vehicle users, only direct costs, fuel tax and some management fees are included, whilst their travelling impacts onto the network and other travellers are both ignored, which leads to the rapid growth in vehicle traffic and congestion (Ferrari 1999). Congestion pricing, which currently has been successfully implicated in Paris, Brussels, Oslo and many other cities, turns out to be an effective approach for alleviating the traffic congestion, reducing traffic pollution and improving traffic efficiency (De Palma et al. 2006).

Traffic behavioural theory provides a novel perspective to better analyse complicated phenomenon in urban road traffic; meanwhile it provides a theoretical basis for investigations on traveller's decision-making behaviour after the implementation of congestion pricing. Most of congesting pricing related researches regarding travel's mode choosing behaviour mainly base on the framework of expected utility theory, which adopts disaggregate logit model, including multinomial logit model (Burris, Pendyala 2002; Álvarez et al. 2007), rank ordered logit model (Calfee, Winston 1998; BenElia, Ettema 2009) and mixed logit model (Brownstone, Small 2005; Small et al. 2006). Expected utility theory assumes that decision maker's attitude toward risk can be rationalized by the expected utility function. It is defined as a function of the utilities associated to the possible outcomes of the options and the probabilities associated to those outcomes. While decision makers are assumed to select the alternative with the maximum expected utility value.

For the lack of analysis and research on the traveller's decision-making behaviour under the uncertain environment, the expected utility theory can not explain travel's mode choice behaviour change when facing time constraints or cost constraints (Hu et al. 2011). Santos et al. (2010) considered that travel behaviour analysis based on individual rational choice will further worsen the transportation and environment issues, the un-

Corresponding author: Xiaowei $\mathrm{Hu}$

E-mails: xiaowei_hu@yahoo.com, hxwhit@163.com 
certainty should be considered in traveller's behaviour analysis.

However, these assumptions made by expected utility theory are clearly different from travellers' behaviours in reality. Therefore, based on Simon's (1955) 'bounded rationality' theory, Kahneman and Tversky (1979) proposed the Prospect Theory in 1979 and its later version, the cumulative prospect theory in 1992 (Tversky, Kahneman 1992). The prospect theory combined individuals' value of feelings characteristics in psychological with individual's decision-making behaviour in reality situations, and thus it is able to describe individual's decisionmaking behaviour under uncertain conditions more accurately (Kahneman, Tversky 1979). Prospect theory has two main parts, one is Reflection Effect, and another is Isolation Effect, both of them deny individual's rational opinion (Kahneman, Tversky 1979; Tversky, Kahneman 1974, 1986, 1992).

According to the prospect theory, individuals' decision-making process can be divided into a two-step process:

- an initial phase of editing;

- a subsequent phase of evaluation.

In the transportation system, a traveller's decisionmaking is a selection process based on judgments and estimations within different kinds of traffic scenarios, such as road congestion, road maintenance, temporary traffic control and adverse weather; all of these uncertain conditions make travel's mode choice decision nonrational and non-stable. Thus it is reasonable to apply prospect theory in modelling travellers' decision-making behaviour since this theory has successfully described the whole decision making process under uncertain conditions. Prospect theory currently has been applied in routing choice behaviour (Avineri, Prashker 2005; Gao et al. 2010; Ben-Elia, Shiftan 2010), commuter departure time choice (Senbil, Kitamura 2004; Jou et al. 2008), and network equilibrium model with traveller's decision-making under risk or uncertain conditions (Avineri 2006; Connors, Sumalee 2009; Wang, Xu 2011). Combining prospect theory and the survey data (stated preference data or real-time information) to analyse the traveller's route choice behaviour, is a new approach for travellers' decision-making process research (Ben-Elia, Shiftan 2010; Xu et al. 2011b; Razo, Gao 2013).

Recently researchers from different perspective summarized the application of prospect theory in the transport participator's behaviour analysis, and analysed the similarities and differences between prospect theory and utility theory in travel behaviour research. Van de Kaa (2010a) provided a comprehensive review of the prospect theory and utility theory on traveller choice behaviour, including the assumptions, framing, judgment, evaluation and choice behaviour strategy. Van de Kaa (2010b) conducted a meta-analysis to evaluate which of these two theories can describe travellers' choice behaviour better, and suggested that an extended prospect theory may receive a better understanding of traveller choice behaviour analysis. Li and Hensher (2011) overviewed the prospect theory in the fields of psychology, behavioural economics and transportation, and identified that the prospect theory condition was more suitable for travel behaviour studies; they also reviewed some behavioural limitations in the transport prospect theory research field.

Based on price principle, congestion pricing helps restrict transport demand and encourage traveller changing mode choice or route choice, with the purpose of reducing traffic congestion and traffic pollution. Congestion pricing analysis based on prospect theory has been paid more attention in recent years. Liu et al. (2010) adopted the cumulative prospect theory and Wardrop's user equilibrium to establish the congestion pricing model. Xu et al. (2011a) presented an optimal pricing model based on a prospect-based user equilibrium model to analyse traveller's behaviour under the congestion pricing condition, which can reflect traveller's choice under the risk environment. Lindsey (2011) assumed that travellers have reference-dependent preferences to analyse state-dependent congestion pricing issue, and found a state-independent toll can be optimal when the gain-loss utility was moderately powerful.

This paper will adopt cumulative prospect theory to analyse car owner's mode choice behaviour under the congestion pricing condition, with considering travellers' attitude at risk condition as well as traveller's learning characteristics during travel process. By investigating travellers' decision-making behaviour under uncertainties conditions, we also address an explanation regarding the travel's mode choice behaviour changing process after the implementation of congestion pricing policy is also drawn.

\section{Car Owner's Mode Choice Behaviour Modelling Based on Cumulative Prospect Theory}

This paper first adopts cumulative prospect theory to analysis car owner's mode choice behaviour after the implementation of congestion pricing policy, which can better explain travel's mode choice behaviour under uncertainty environment. Here we consider the travellers' generalized cost and reference point selection to represent car owner's mode choice behaviour process.

\subsection{Modelling Process}

Before initializing a real-world trip, travellers first need to calculate all transportation modes' prospect value, and then select one with the greatest prospect value from all the options to complete the trip. In a real-world transportation network, although there could be several transportation modes from the traveller's origin to destination; the paper only takes into consideration the longdistance travel in the city, including public bus, taxi, subway and private cars mode. Travellers' mode choice decision can follow the following steps:

- edit the mode choice problem and select the reference point of decision-making;

- estimate the possible results (gains or losses) of four kinds of transportation modes, with the result of events arranged by increasing order, and 


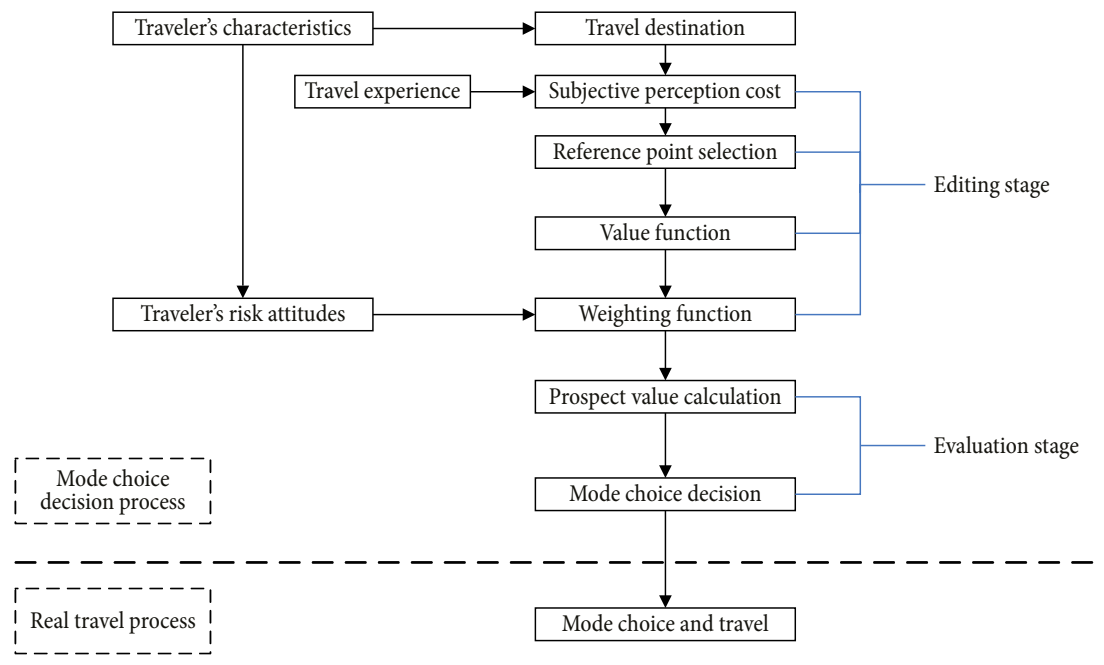

Fig. 1. Modelling and analysing framework of travel's mode choice behaviour based on cumulative prospect theory

then judge the subjective probability of the results;

- in accordance with the cumulative prospect theory, use the value function and the decision weights function to calculate prospect of each mode, and select the maximum prospect mode to complete the trip.

According to the analysis of travel's mode choice behaviour based on cumulative prospect theory, Fig. 1 shows the detailed modelling and analysing framework.

\subsection{Car Owner's Subjective Perception Cost}

Travellers will judge each transportation mode and estimate their own trip costs before they make their mode choice decisions. Factors that affect travel's mode choices include travel time, cost, safety, and so on, while the travel time can be translated into cost by combining with value of time. This paper considers different value of time traveller's mode choice and assumes travellers have to arrive at destination before work start time $T_{\text {work }}$, while early arrival and late arrival will both generate the related losses respectively. According to the study of Small (1982), the trip cost can be listed below:

- charging cost of each transportation mode refers to the cost from the origin to the destination, such as bus fares, taxi fares, subway fares, and private car parking fee and fuel cost;

- travel time cost refers to the costs incurred from the origin to the destination, including the cost related with in-vehicle time and walking time;

- tardiness penalties refer to the penalty cost incurred from travellers' failure of reaching destination on time, because of the fact that either early arrival or late arrival will generate penalty cost anyway.

Supposing a traveller enters the transportation network at time $T_{o}$, the arrival time made by subjective perception is $T_{\text {arrival }}$, and working start time is $T_{\text {work. }}$. If $T_{\text {arrival }} \leq T_{\text {work }}$ will generate early penalty costs; otherwise, it will generate delay penalty costs:

$$
T_{\text {arrival }}=T_{o}+\hat{t}_{\text {trip }}^{o},
$$

where: $\hat{t}_{\text {trip }}^{o}$ is traveller's trip time from origin to destination.

The generalized cost of traveller from the decisionmaking node to destination has the following cost components:

$$
\begin{aligned}
& U=U_{j}+U_{\text {trip }}+U_{\text {early }}+U_{\text {late }} ; \\
& U_{\text {trip }}=\theta_{\text {trip }} \cdot \hat{t}_{\text {trip }}^{o} ; \\
& U_{\text {early }}=\delta \cdot \theta_{\text {early }} \cdot\left(T_{\text {work }}-T_{\text {arrival }}\right) ; \\
& U_{\text {late }}=(1-\delta) \cdot \theta_{\text {late }} \cdot\left(T_{\text {arrival }}-T_{\text {work }}\right),
\end{aligned}
$$

where: $U, U_{j}, U_{\text {trip }}, U_{\text {early }}, U_{\text {late }}$ denote the generalized cost, charging cost of each transportation mode, travel time cost, early penalty cost, and delay penalty cost, respectively; $\theta_{\text {trip }}, \theta_{\text {early }}, \theta_{\text {late }}$ denotes the unit time cost of travel time, the early arrival penalty unit time cost, and the late arrival penalty unit time cost, respectively.

According to Small's (1982) study, we have $\theta_{\text {late }}>\theta_{\text {trip }}>\theta_{\text {early }} . \delta$ is a binary variable, and $\delta=0$ if $T_{\text {arrival }}>T_{\text {work }}$; otherwise, $\delta=1$ if $T_{\text {arrival }} \leq T_{\text {work }}$.

The value of charging cost for each transportation modes can be set as $U_{b u s}=2, U_{c a r}=10+1 \cdot d$, $U_{\text {subway }}=5$ and $U_{\text {taxi }}=4+1.5 \cdot(d-2)$, when $d>2$ respectively, where $d$ refers to the trip distance [kilometres].

From analysis above we can obtain traveller's subjective generalized cost $U$ at the decision-making node as follows:

$$
\begin{aligned}
& U=U_{j}+\left(\theta_{\text {trip }}-\delta \cdot \theta_{\text {early }}+(1-\delta) \cdot \theta_{\text {late }}\right) \cdot \hat{t}_{\text {trip }}^{o}+ \\
& \left(\delta \cdot \theta_{\text {early }}-(1-\delta) \cdot \theta_{\text {late }}\right) \cdot\left(T_{\text {work }}-T_{o}\right) .
\end{aligned}
$$

The traveller's subjective generalized cost not only considers the transportation modes fare and the travel time cost, but also includes the early penalty cost or delay penalty cost, which can reflect traveller's real subjective experience and cost. 


\subsection{Reference Point Selection}

Reference point selection is the essential of prospect theory; in this step, travellers will measure the gain or loss to the reference point when making their decisions. Setting traveller's departure time is $T_{o}$, and the expected destination arrival time is $T_{\text {expected }}$. If traveller arrives at the decision-making node $o$ at $T_{o}$, then the expected travel time between the decision-making node and the destination is $t_{\text {expected }}^{o}=T_{\text {expected }}-T_{o}$, at this stage the expected travel costs is $U_{\text {expected }}^{o}$. From Eq. (6) we can get the following equation:

$$
\begin{aligned}
& U\left(t_{\text {expected }}^{o}\right)=U_{j}+ \\
& \left(\theta_{\text {trip }}-\delta \cdot \theta_{\text {early }}+(1-\delta) \cdot \theta_{\text {late }}\right) \cdot t_{\text {expected }}^{o}+ \\
& \left(\delta \cdot \theta_{\text {early }}-(1-\delta) \cdot \theta_{\text {late }}\right) \cdot\left(T_{\text {work }}-T_{o}\right) .
\end{aligned}
$$

$U\left(t_{\text {expected }}^{o}\right)$ is the expected travel cost at reference point when traveller is making decision.

Setting traveller's subjective estimates of arriving time by transportation mode $j$ is $\hat{T}_{j}$, then the estimated travel time is $\hat{t}_{j}^{o}=\hat{T}_{j}-T_{o}$. From Eq. (6) we can get traveller's subjective perception cost:

$$
\begin{aligned}
& U\left(\hat{t}_{j}^{o}\right)=U_{j}+\left(\theta_{\text {trip }}-\delta \cdot \theta_{\text {early }}+(1-\delta) \cdot \theta_{\text {late }}\right) \cdot \hat{t}_{j}^{o}+ \\
& \left(\delta \cdot \theta_{\text {early }}-(1-\delta) \cdot \theta_{\text {late }}\right) \cdot\left(T_{\text {work }}-T_{o}\right)
\end{aligned}
$$

Traveller will compare the subjective perceptions cost $U\left(\hat{t}_{j}^{o}\right)$ and the expectations cost $U\left(t_{\text {expected }}^{o}\right)$ to weigh the pros and cons. If $U\left(\hat{t}_{j}^{o}\right) \leq U\left(t_{\text {expected }}^{o}\right)$, traveller will get gains; otherwise, $U\left(\hat{t}_{j}^{o}\right)>U\left(t_{\text {expected }}^{o}\right)$, traveller will suffer a loss.

From Eq. (7) and Eq. (8), we can get $x_{0}$ :

$x_{o}=U\left(t_{\text {expected }}^{o}\right)-U\left(\hat{t}_{j}^{o}\right)=$

$\begin{cases}\left(\theta_{\text {trip }}-\theta_{\text {early }}\right) \cdot\left(t_{\text {expected }}^{o}-\hat{t}_{j}^{o}\right), & \text { if } \hat{t}_{j}^{o} \leq t_{\text {expected }}^{o}, \quad x_{o} \geq 0 ; \\ \left(\theta_{\text {trip }}+\theta_{\text {late }}\right) \cdot\left(t_{\text {expected }}^{o}-\hat{t}_{j}^{o}\right), & \text { if } \hat{t}_{j}^{o}>t_{\text {expected }}^{o}, \quad x_{o}<0 .\end{cases}$

where: $x_{o}$ represents the traveller subjective perceptions about transportation mode $j$ getting gains or losses at decision stage $o$.

\subsection{Prospect Value Calculation and Mode Choice Decision}

Referring to the research of Tversky and Kahneman (1992), and Avineri (2006), the Appendices 1-3 show the Value Function, Weighted Function and Prospect Value Calculation process, respectively. From the above analysis and Fig. 1, we can obtain the different transportation modes' prospect values and make the mode choice decisions.

\section{Example Analysis of Car Owner's Mode Choice Behaviour before and after the Implementation of Congestion Pricing}

\subsection{Basic Assumptions}

Supposing that the distance between origin and destination is 8 kilometres, the per unit time costs of different incoming traveller groups are also different. Referring to Qi et al. (2008), Jiang et al. (2009) and Zong et al. (2009), different values of time traveller's parameters are shown in Table 1 (here we assume different values of time travellers all work 8 hours per day). Traveller's estimations on the travel time of different modes are shown in $\mathrm{Ta}$ ble 2 (Hu et al. 2011).

According to China Statistical Yearbook from 2002 to 2010, statistical data show that the consumption expenditure of urban residents on the transportation and communications' proportion is between $10.4 \%$ and $13.6 \%$. Mei (2010) illustrated the consumption structure of urban residents from 2004 to 2006. The low, medium and high consumption level of residents spent on transportation and telecommunication range from $11.7 \%$ to $13.0 \%, 13.0 \%$ to $14.4 \%$, and $14.0 \%$ to $15.4 \%$ respectively, within residents' actual money expenditure. By the assumption on value of time traveller's parameters in Table 1 and the assumption on the charging fare of several transportation modes in Section 1.2, traveller will adopt principle of 'moderate cost with the shortest time' to make mode choice. Assuming that travellers' wealth constraint is always below $120 \%$ of their income per hour; thus for medium and high income groups, their monetary costs can meet all the four kinds of transportation modes.

Table. 1 Different levels of car owner's parameters

\begin{tabular}{ccccc}
\hline $\begin{array}{c}\text { Income } \\
\text { class }\end{array}$ & $\begin{array}{c}\text { Income } \\
\text { level }[¥ / \mathrm{h}]\end{array}$ & $\begin{array}{c}\theta_{\text {late }} \\
{[¥ / \mathrm{min}]}\end{array}$ & $\begin{array}{c}\theta_{\text {trip }} \\
{[¥ / \mathrm{min}]}\end{array}$ & $\begin{array}{c}\theta_{\text {early }} \\
{[¥ / \mathrm{min}]}\end{array}$ \\
\hline Middle & 18 & 0.35 & 0.30 & 0.25 \\
\hline High & 24 & 0.50 & 0.40 & 0.30 \\
\hline
\end{tabular}

Table. 2 Traveller's estimation on different modes' travel time

\begin{tabular}{lcccccccccc}
\hline & & & & & & & & & \\
\hline Bus & $0 \%$ & $5 \%$ & $10 \%$ & $10 \%$ & $10 \%$ & $25 \%$ & $30 \%$ & $5 \%$ & $5 \%$ \\
\hline Subway & $10 \%$ & $20 \%$ & $30 \%$ & $20 \%$ & $10 \%$ & $10 \%$ & 0 & 0 & 0 \\
\hline Taxi & $20 \%$ & $40 \%$ & $30 \%$ & $10 \%$ & 0 & 0 & 0 & 0 & 0 \\
\hline Car & $85 \%$ & $5 \%$ & $5 \%$ & $5 \%$ & 0 & 0 & 0 & 0 & 0 \\
\hline
\end{tabular}

\subsection{Analysis of Car Owner's Mode Choice Behaviour before the Congestion Pricing}

Supposing that traveller's travel time expectation towards different transportation modes are 30 minutes by bus, 20 minutes by subway, 15 minutes by taxi, and 12 minutes by car. In the following part, different levels of car owners' mode prospect values are calculated, and 
comparison with the results of expected utility theory is also addressed.

From Eqs (6) and (7), we can calculate the generalized travel cost of reference point as follow, i.e. $U\left(t_{\text {expected }}^{o}\right)$ :

Bus:

$$
\begin{aligned}
& U_{\text {bus }}\left(\hat{t}_{\text {expected }}^{o}\right)=2+\theta_{\text {trip }} \cdot \hat{t}_{\text {trip }}^{o}= \\
& 2+\theta_{\text {trip }} \cdot \hat{t}_{\text {expected }}^{o}=2+30 \cdot \theta_{\text {trip }} .
\end{aligned}
$$

Subway:

$$
\begin{aligned}
& U_{\text {subway }}\left(\hat{t}_{\text {expected }}^{o}\right)=5+\theta_{\text {trip }} \cdot \hat{t}_{\text {trip }}^{o}= \\
& 4+\theta_{\text {trip }} \cdot \hat{t}_{\text {expected }}^{o}=5+20 \cdot \theta_{\text {trip }} .
\end{aligned}
$$

Taxi:

$$
\begin{aligned}
& U_{\text {taxi }}\left(\hat{t}_{\text {expected }}^{o}\right)=13+\theta_{\text {trip }} \cdot \hat{t}_{\text {trip }}^{o}= \\
& 13+\theta_{\text {trip }} \cdot \hat{t}_{\text {expected }}^{o}=13+15 \cdot \theta_{\text {trip }} .
\end{aligned}
$$

Car:

$$
\begin{aligned}
& U_{\text {car }}\left(\hat{t}_{\text {expected }}^{o}\right)=18+\theta_{\text {trip }} \cdot \hat{t}_{\text {trip }}^{o}= \\
& 18+\theta_{\text {trip }} \cdot \hat{t}_{\text {expected }}^{o}=18+12 \cdot \theta_{\text {trip }} .
\end{aligned}
$$

Based on Eq. (8), the traveller's subjective perception cost $\hat{U}_{j}^{o}$ can be given:

Bus:

$$
\begin{aligned}
& U_{\text {bus }}\left(\hat{t}_{j}^{o}\right)=2+ \\
& \left(\theta_{\text {trip }}-\delta \cdot \theta_{\text {early }}+(1-\delta) \cdot \theta_{\text {late }}\right) \cdot \hat{t}_{j}^{o}+ \\
& \left(\delta \cdot \theta_{\text {early }}-(1-\delta) \cdot \theta_{\text {late }}\right) \cdot 30 .
\end{aligned}
$$

Subway:

$$
\begin{aligned}
& U_{\text {subway }}\left(\hat{t}_{j}^{o}\right)=5+ \\
& \left(\theta_{\text {trip }}-\delta \cdot \theta_{\text {early }}+(1-\delta) \cdot \theta_{\text {late }}\right) \cdot \hat{t}_{j}^{o}+ \\
& \left(\delta \cdot \theta_{\text {early }}-(1-\delta) \cdot \theta_{\text {late }}\right) \cdot 20 .
\end{aligned}
$$

Taxi:

$$
\begin{aligned}
& U_{\text {taxi }}\left(\hat{t}_{j}^{o}\right)=13+ \\
& \left(\theta_{\text {trip }}-\delta \cdot \theta_{\text {early }}+(1-\delta) \cdot \theta_{\text {late }}\right) \cdot \hat{t}_{j}^{o}+ \\
& \left(\delta \cdot \theta_{\text {early }}-(1-\delta) \cdot \theta_{\text {late }}\right) \cdot 15 .
\end{aligned}
$$

\begin{tabular}{|c|c|c|c|c|c|}
\hline \multirow{2}{*}{ Stage } & \multirow{2}{*}{$\begin{array}{l}\text { Passenger } \\
\text { transpor- } \\
\text { tation } \\
\text { mode }\end{array}$} & \multicolumn{2}{|c|}{$\begin{array}{l}\text { Expected utility } \\
\text { theory }\end{array}$} & \multicolumn{2}{|c|}{$\begin{array}{l}\text { Cumulative } \\
\text { prospect theory }\end{array}$} \\
\hline & & $\begin{array}{l}\text { Middle } \\
\text { income }\end{array}$ & $\begin{array}{l}\text { High } \\
\text { income }\end{array}$ & $\begin{array}{l}\text { Middle } \\
\text { income }\end{array}$ & $\begin{array}{l}\text { High } \\
\text { income }\end{array}$ \\
\hline \multirow{4}{*}{ 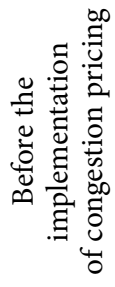 } & Bus & 11.083 & 13.985 & -0.736 & -0.903 \\
\hline & Subway & 11.725 & 13.930 & -1.215 & -1.569 \\
\hline & Taxi & 18.445 & 20.290 & -1.755 & -2.312 \\
\hline & Car & 22.185 & 23.610 & -1.078 & -1.435 \\
\hline \multirow{4}{*}{ 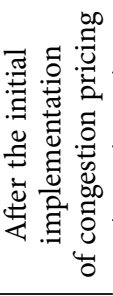 } & Bus & 11.083 & 13.985 & -0.736 & -0.903 \\
\hline & Subw & 11.725 & 13.930 & -1.215 & -1.569 \\
\hline & Taxi & 18.445 & 20.290 & -1.755 & -2.312 \\
\hline & Car & 27.185 & 28.610 & -10.381 & -10.794 \\
\hline \multirow{4}{*}{ 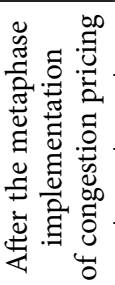 } & Bus & 10.880 & 13.700 & -0.732 & -0.894 \\
\hline & Subway & 11.725 & 13.930 & -1.215 & -1.569 \\
\hline & Taxi & 18.040 & 19.720 & -1.277 & -1.669 \\
\hline & Car & 26.893 & 28.205 & -0.642 & -0.855 \\
\hline
\end{tabular}

Car:

$$
\begin{aligned}
& U_{\text {car }}\left(\hat{t}_{j}^{o}\right)=18+ \\
& \left(\theta_{\text {trip }}-\delta \cdot \theta_{\text {early }}+(1-\delta) \cdot \theta_{\text {late }}\right) \cdot \hat{t}_{j}^{o}+ \\
& \left(\delta \cdot \theta_{\text {early }}-(1-\delta) \cdot \theta_{\text {late }}\right) \cdot 12 .
\end{aligned}
$$

In accordance with the expected utility theories utility maximization hypothesis and prospect theory, different expected utility values and prospect values for different values of time traveller' modes are calculated, and the results are shown in Table 3.

For car owners, according to expected utility theory calculations, travellers will give priority to bus and subway, while actually travellers will prefer to private cars, which is involved with different levels of car owners' privacy and time requirements. Therefore, according to cu-
Table 3. Different levels of car owner's mode choice under different circumstances

mulative prospect theory's results, priority of private cars is higher than subway and taxi, but lower than bus. The high value-of-time travellers usually pay less attention to transportation mode's fare (cost), but hope to reach the destination node within a short period of time. In reality, car owners will select the private car as priority, and then bus, subway and the others. They are less likely to choose bus for the reason of less expensive fares and longer travel time.

\subsection{Analysis of Car Owner's Mode Choice Behaviour after the Congestion Pricing}

\subsubsection{The initial Phase of the Implementation of Congestion Pricing}

Assuming that the congestion pricing on private car is $¥ 5$, here we analyse the change of different values of time traveller' mode choice behaviours. Because subway is not affected by road transportation network, whose estimated travel time and probability is relatively stable (Table 2). The middle income class and high income class will be affected, namely, the generalized travel cost of reference point $U\left(t_{\text {expected }}^{o}\right)$ will remain the same, while the traveller's subjective perception cost $\hat{U}_{j}^{o}$ will change. These results are also shown in Table 3.

From Table 3, we can find that expected utility value of private car increases in expected utility theory, but travellers' mode choice priority still remains the same. And from results of cumulative prospect theory, car owners' mode choice has changed greatly. As pros- 
pect value of private car decreases rapidly, travellers' loss has been through a considerable increase, which leads to some alternations, from private car to another transportation mode with less loss, like bus and subway.

\subsubsection{The Metaphase of the Implementation of Congestion Pricing}

In the metaphase of congestion pricing, subway's estimated travel time and probability tend to be stable, while the travel time of car, bus and taxi are impacted by congestion pricing. Here assuming that in the congestion pricing metaphase, the car owner's estimation on private car, taxi and conventional bus's travel time and probabilities have changed. The changing of travellers' estimation towards the travel time of different modes is shown in Table 4. In accordance with the utility maximization hypothesis from expected utility theory and prospect theory, different values of time traveller' mode expected utility value and prospect value are calculated, and the results are also shown in Table 3.

Table 4. Traveller's estimation on different modes' travel time changing

\begin{tabular}{lccccccccc}
\hline $\begin{array}{c}\text { Travel } \\
\text { time } \\
\text { [min] }\end{array}$ & 12 & 15 & 18 & 21 & 24 & 27 & 30 & 33 & 36 \\
\hline Bus & $0 \%$ & $5 \%$ & $10 \%$ & $10 \%$ & $15 \%$ & $20 \%$ & $30 \%$ & $5 \%$ & $5 \%$ \\
\hline Subway & $10 \%$ & $20 \%$ & $30 \%$ & $20 \%$ & $10 \%$ & $10 \%$ & 0 & 0 & 0 \\
\hline Taxi & $30 \%$ & $50 \%$ & $10 \%$ & $10 \%$ & 0 & 0 & 0 & 0 & 0 \\
\hline Car & $93 \%$ & $5 \%$ & $2 \%$ & $0 \%$ & 0 & 0 & 0 & 0 & 0 \\
\hline
\end{tabular}

As travellers' estimation on the travel time and probability of bus, taxis and car change, expected utility theory results and mode choice behaviour of high income class change as well. This results in the priority exchange of subway and bus. It can be attributed to the ability of congestion pricing, which improves road network efficiency, reduces road traffic congestion and thus improves bus running speed, bus traveling time, and increases the reliability. On the other hand, it also illustrates the need for subway service improvement after the implementation of congestion pricing policy, in order to shorten travel time and increase travel speed.

According to the results of cumulative prospect theory, different levels of car owners' transportation mode's prospect values have been changed, while subway's prospect value remains the same, therefore it becomes the smallest one among travellers' class. Car owners will first choose car, then bus, taxi and subway. Therefore congestion pricing policy will surely force subway to improve service quality. On the other hand, after the implementation of congestion policy for a certain period, car owners will still choose private car because of the reduced road congestion, improved travel speed, and shorten travel time.

\section{Stated Preference Survey}

We have carried out the Stated Preference surveys (Diana 2010), in order to obtain different traveller' mode choice information. We have sent 150 questionnaires through email to the survey traffic engineers, and got 105 replies back. The final available sample size is 98 ; Table 5 shows the socioeconomic characteristics of samples.

From Fig. 2 we can find that after the implementation of congestion pricing policy, travellers will change their mode choices, especially the car mode choice proportion reduced sharply, and comparatively they would like to choose taxi. The experience of London (Prud'homme, Bocarejo 2005), and Stockholm (Eliasson et al. 2009) have shown the bus route re-schedule, park and ride transfer service, as well as the fare integration will be helpful with the implementation of congestion pricing. The management authority should consider the ridership changing and provide convenient transfer service.

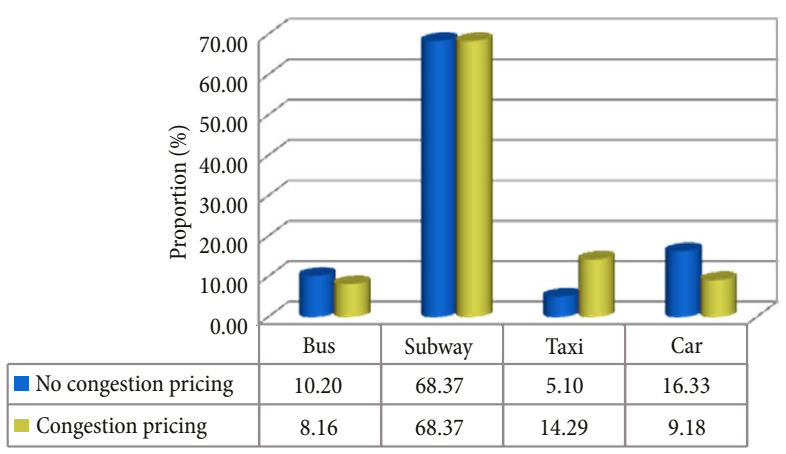

Fig. 2. Travel's mode choice before and after the implementation of congestion pricing

Table 5. Socioeconomic characteristics of survey samples

\begin{tabular}{llc}
\hline \multicolumn{1}{c}{ Attribute } & \multicolumn{1}{c}{ Range } & Frequency [\%] \\
\hline \multirow{2}{*}{ Gender } & Male & 71.43 \\
& Female & 28.57 \\
\hline \multirow{4}{*}{ Age group } & $<25$ & 8.16 \\
& $25-29$ & 73.47 \\
& $30-34$ & 14.29 \\
& $>35$ & 4.08 \\
\hline \multirow{4}{*}{ Educational level } & College graduate & 26.53 \\
& Post graduate & 59.18 \\
& PhD & 14.29 \\
\hline \multirow{5}{*}{ Income per month } & Less than $¥ 1500$ & 18.37 \\
& $¥ 1500-¥ 2999$ & 22.45 \\
& $¥ 4500-¥ 4499$ & 19.39 \\
& More than $¥ 6000$ & 10.20 \\
& Do not own a car & 29.59 \\
\hline \multirow{3}{*}{ Car ownership } & Own one car & 85.71 \\
& Own two or more cars & 12.25 \\
\end{tabular}

Note: US \$ 1 dollar $=6.31$ Yuan $(¥)$ conversion in April 2012

During the stated preference survey process, respondents have expressed their concerns on the allocation of congestion pricing revenue; and they believe that a reasonable and transparent allocation of the revenue will increase public support and policy acceptance. The existing researches have also proved that the allocation 
of congestion pricing revenue will improve public transport, reduce existing vehicle-related taxes, and facilitate public acceptance of the congestion pricing policy, see Farrell and Saleh (2005), Schuitema and Steg (2008), Eliasson et al. (2009), and Börjesson et al. (2012).

\section{Conclusions}

With the uncertainty existing in the traffic environment, travel's mode choice behaviour is changing and not regular. Cumulative prospect theory can describe individual's decision-making characteristics and individual's psychological status under the uncertain scenario, which makes the application of cumulative prospect theory in the modelling travel's mode choice behaviour more suitable for traveller's psychological expectations, as well as the travel's mode choice behaviour changing.

By introducing the cumulative prospect theory into analysis of different levels of car owners' mode choice behaviour, this paper compared the similarities and difference of expected utility theory and cumulative prospect theory on the describing travel's mode choice behaviours. The cumulative prospect theory was more suitable for analysing car owner's mode choice decisionmaking behaviour under uncertain and risk situation. With the consideration of traveller's perception cost and risk value, this model can also be adopted in the analysis and evaluation of other passenger transportation management economic policy changing, such as the parking fee, bus/subway fare and oil price.

The results of numerical example have shown that after the implementation of congestion pricing policy, car owner's mode choice decision-making behaviour will change and shift to public transportation (such as subway, taxi and public bus). Therefore, the management authority of passenger transportation should reschedule the service frequency of subway (public bus), re-planning the bus lines and taxi waiting stops, and develop the Park and Ride facilities.

The future work can be conducted to combine with the Agent based model and analyse the impact of different congestion pricing level on travel's mode choice behaviour, as well as the management authority's social effect, including the environmental protection, energy consumption and total travel time.

\section{Acknowledgements}

This research is supported by National Natural Science Foundation of China (Project No. 71073035, 70973032 and 71203045) and Program for New Century Excellent Talents in University (NCET-10-0065).

The authors would like to thank many researchers and engineers for their assistance in the survey.

The authors would like to express their sincere thanks to Prof. Yanfeng Ouyang (University of Illinois at Urbana-Champaign) for helpful comments and valuable suggestions on this paper.

\section{References}

Álvarez, Ó.; Cantos, P.; García, L. 2007. The value of time and transport policies in a parallel road network, Transport Policy 14(5): 366-376. http://dx.doi.org/10.1016/j.tranpol.2007.04.012

Avineri, E. 2006. The effect of reference point on stochastic network equilibrium, Transportation Science 40(4): 409420. http://dx.doi.org/10.1287/trsc.1060.0158

Avineri, E.; Prashker, J. N. 2005. Sensitivity to travel time variability: travelers' learning perspective, Transportation Research Part C: Emerging Technologies 13(2): 157-183. http://dx.doi.org/10.1016/j.trc.2005.04.006

Ben-Elia, E.; Ettema, D. 2009. Carrots versus sticks: Rewarding commuters for avoiding the rush-hour - a study of willingness to participate, Transport Policy 16(2): 68-76. http://dx.doi.org/10.1016/j.tranpol.2009.03.005

Ben-Elia, E.; Shiftan, Y. 2010. Which road do I take? A learning-based model of route-choice behavior with real-time information, Transportation Research Part A: Policy and Practice 44(4): 249-264. http://dx.doi.org/10.1016/j.tra.2010.01.007

Börjesson, M.; Eliasson, J.; Hugosson, M. B.; Brundell-Freij, K. 2012. The Stockholm congestion charges -5 years on. Effects, acceptability and lessons learnt, Transport Policy 20: 1-12. http://dx.doi.org/10.1016/j.tranpol.2011.11.001

Brownstone, D.; Small, K. A. 2005. Valuing time and reliability: assessing the evidence from road pricing demonstrations, Transportation Research Part A: Policy and Practice 39(4): 279-293. http://dx.doi.org/10.1016/j.tra.2004.11.001

Burris, M. W.; Pendyala, R. M. 2002. Discrete choice models of traveler participation in differential time of day pricing programs, Transport Policy 9(3): 241-451. http://dx.doi.org/10.1016/S0967-070X(02)00002-1

Calfee, J.; Winston, C. 1998. The value of automobile travel time: implications for congestion policy, Journal of Public Economics 69(1): 83-102. http://dx.doi.org/10.1016/S0047-2727(97)00095-9

Connors, R. D.; Sumalee, A. 2009. A network equilibrium model with travellers' perception of stochastic travel times, Transportation Research Part B: Methodological 43(6): 614624. http://dx.doi.org/10.1016/j.trb.2008.12.002

De Palma, A.; Lindsey, R.; Proost, S. 2006. Research challenges in modelling urban road pricing: an overview, Transport Policy 13(2): 97-105.

http://dx.doi.org/10.1016/j.tranpol.2005.11.006

Diana, M. 2010. From mode choice to modal diversion: A new behavioural paradigm and an application to the study of the demand for innovative transport services, Technological Forecasting and Social Change 77(3): 429-441. http://dx.doi.org/10.1016/j.techfore.2009.10.005

Eliasson, J.; Hultkrantz, L.; Nerhagen, L.; Rosqvist, L. S. 2009. The Stockholm congestion - charging trial 2006: overview of effects, Transportation Research Part A: Policy and Practice 43(3): 240-250. http://dx.doi.org/10.1016/j.tra.2008.09.007

Farrell, S.; Saleh, W. 2005. Road-user charging and the modelling of revenue allocation, Transport Policy 12(5): 431-442. http://dx.doi.org/10.1016/j.tranpol.2005.06.003

Ferrari, P. 1999. A model of urban transport management, Transportation Research Part B: Methodological 33(1): 4361. http://dx.doi.org/10.1016/S0191-2615(98)00027-7 
Gao, S.; Frejinger, E.; Ben-Akiva, M. 2010. Adaptive route choices in risky traffic networks: A prospect theory approach, Transportation Research Part C: Emerging Technologies 18(5): 727-740.

http://dx.doi.org/10.1016/j.trc.2009.08.001

Hu, X.-W.; Wang, J.; Sun, G.-L. 2011. Traveler's mode choice behavior analysis under bounded rational, Journal of Harbin Institute of Technology 43(12): 1569-1573. (in Chinese).

Jiang, Y.; Li, T.; Di Bona, R. F. 2009. Value of travel time: an SP survey in Tianjin, Urban Transport of China 7(2): 68-73. (in Chinese).

Jou, R.-C.; Kitamura, R.; Weng, M.-C.; Chen, C.-C. 2008. Dynamic commuter departure time choice under uncertainty, Transportation Research Part A: Policy and Practice 42(5): 774-783. http://dx.doi.org/10.1016/j.tra.2008.01.017

Kahneman, D.; Tversky, A. 1979. Prospect theory: an analysis of decision under risk, Econometrica 47(2): 263-292. http://dx.doi.org/10.2307/1914185

Li, Z.; Hensher, D. 2011. Prospect theoretic contributions in understanding traveller behaviour: a review and some comments, Transport Reviews 31(1): 97-115. http://dx.doi.org/10.1080/01441647.2010.498589

Lindsey, R. 2011. State-dependent congestion pricing with reference-dependent preferences, Transportation Research Part B: Methodological 45(10): 1501-1526. http://dx.doi.org/10.1016/j.trb.2011.06.003

Liu, Y.; Liu, W.; Hu, Y.; Li, J. 2010. Pricing model of traffic demand management based on cumulative prospect theory, in 2010 8th World Congress on Intelligent Control and Automation (WCICA), 6-9 July 2010, Jinan, China, 5175-5180. http://dx.doi.org/10.1109/WCICA.2010.5554903

Mei, H. 2010. On the optimization of the total consumption amount of domestic residents and structure, Chinese Journal of Management 7(1): 69-74. (in Chinese).

Prud'homme, R.; Bocarejo, J. P. 2005. The London congestion charge: a tentative economic appraisal, Transport Policy 12(3): 279-287. http://dx.doi.org/10.1016/j.tranpol.2005.03.001

Qi, T.-Y.; Liu, D.-M.; Liu, Y. 2008. A study of the traveling time cost of Beijing residents, Journal of Highway and Transportation Research and Development 25(6): 144-146. (in Chinese).

Razo, M.; Gao, S. 2013. A rank-dependent expected utility model for strategic route choice with stated preference data, Transportation Research Part C: Emerging Technologies 27: 117-130. http://dx.doi.org/10.1016/j.trc.2011.08.009

Santos, G.; Behrendt, H.; Teytelboym, A. 2010. Part II: Policy instruments for sustainable road transport, Research in Transportation Economics 28(1): 46-91. http://dx.doi.org/10.1016/j.retrec.2010.03.002

Schuitema, G.; Steg, L. 2008. The role of revenue use in the acceptability of transport pricing policies, Transportation Research Part F: Traffic Psychology and Behaviour 11(3): 221-231. http://dx.doi.org/10.1016/j.trf.2007.11.003

Senbil, M.; Kitamura, R. 2004. Reference points in commuter departure time choice: a prospect theoretic test of alternative decision frames, Journal of Intelligent Transportation Systems: Technology, Planning, and Operations 8(1): 19-31. http://dx.doi.org/10.1080/15472450490437726

Simon, H. A. 1955. A behavioral model of rational choice, The Quarterly Journal of Economics 69(1): 99-118. http://dx.doi.org/10.2307/1884852

Small, K. A. 1982. The scheduling of consumer activities: work trips, The American Economic Review 72(3): 467-479.
Small, K. A.; Winston, C.; Yan, J. 2006. Differentiated road pricing, express lanes, and carpools: exploiting heterogeneous preferences in policy design, Brookings-Wharton Papers on Urban Affairs 2006: 53-96.

http://dx.doi.org/10.1353/urb.2006.0027

Tversky, A.; Kahneman, D. 1992. Advances in prospect theory: cumulative representation of uncertainty, Journal of Risk and Uncertainty 5(4): 297-323.

http://dx.doi.org/10.1007/BF00122574

Tversky, A.; Kahneman, D. 1986. Rational choice and the framing of decisions, The Journal of Business 59(4): S251-S278. http://dx.doi.org/10.1086/296365

Tversky, A.; Kahneman, D. 1974. Judgment under uncertainty: heuristics and biases, Science 185(4157): 1124-1131. http://dx.doi.org/10.1126/science.185.4157.1124

Van de Kaa, E. J. 2010a. Prospect theory and choice behaviour strategies: review and synthesis of concepts from social and transport sciences, European Journal of Transport and Infrastructure Research 10(4): 299-329.

Van de Kaa, E. J. 2010b. Applicability of an extended prospect theory to travel behaviour research: a meta-analysis, Transport Reviews 30(6): 771-804. http://dx.doi.org/10.1080/01441647.2010.486907

Wang, Q.; Xu, W. 2011. A user equilibrium model based on cumulative prospect theory for degradable transport network, in CSO 2011: Fourth International Joint Conference on Computational Sciences and Optimization, 15-19 April 2011, Yunnan, China, 1078-1082. http://dx.doi.org/10.1109/CSO.2011.62

Xu, H.; Lou, Y.; Yin, Y.; Zhou, J. 2011a. A prospect-based user equilibrium model with endogenous reference points and its application in congestion pricing, Transportation Research Part B: Methodological 45(2): 311-328. http://dx.doi.org/10.1016/j.trb.2010.09.003

$\mathrm{Xu}, \mathrm{H}$.; Zhou, J.; Xu, W. 2011b. A decision-making rule for modeling travelers' route choice behavior based on cumulative prospect theory, Transportation Research Part C: Emerging Technologies 19(2): 218-228.

http://dx.doi.org/10.1016/j.trc.2010.05.009

Zong, F.; Juan, Z.-C.; Zhang, H.-Y.; Jia, H.-F. 2009. Calculation and application of value of travel time, Journal of Transportation Systems and Engineering and Information Technology 9(3): 114-119. (in Chinese). 


\section{APPENDIX 1}

Value Function

Prospect theory adopts value function to replace the utility function of expected utility theory, according to Tversky and Kahneman (1992), traveller's value function at decision stage $o$ can be defined as follows:

$$
v\left(x_{o}\right)=\left\{\begin{array}{cl}
x_{o}^{\alpha}, & \text { if } x_{o} \geq 0 \\
-\lambda\left(-x_{o}\right)^{\beta}, & \text { if } x_{o}<0,
\end{array}\right.
$$

where: $\alpha$ and $\beta$ measures the degree of diminishing sensitivity; $\lambda$ describes the degree of loss aversion.

According to Tversky and Kahneman (1992): $\alpha=$ $\beta=0.88, \lambda=2.25, v\left(x_{0}\right)=v(0)=0$.

\section{APPENDIX 2}

\section{Weighted Function}

The Weighted functions proposed by Tversky and Kahneman (1992) for gains and losses are as follows respectively:

$$
\begin{aligned}
& w^{+}(p)=\frac{p^{\gamma}}{\left(p^{\gamma}+(1-p)^{\gamma}\right)^{1 / \gamma}} \\
& w^{-}(p)=\frac{p^{\chi}}{\left(p^{\chi}+(1-p)^{\chi}\right)^{1 / \chi}},
\end{aligned}
$$

where: $p$ is the probability of gains and losses.

According to Tversky and Kahneman (1992): $\gamma=$ $0.61, \chi=0.69, w^{+}(0)=w^{-}(0)=0, w^{+}(1)=w^{-}(1)=1$.

\section{APPENDIX 3}

\section{Prospect Value Calculation}

Tversky and Kahneman (1992) developed a version of prospect theory that employs cumulative rather than separable decision weights. This version, cumulative prospect theory, applies to describe uncertainty as well as to risky prospects with any number of outcomes. $\mathrm{Cu}$ mulative prospect theory utilizes the cumulative function to demonstrate gains and to losses respectively. An uncertain prospect $f$ is a function from a finite set of states of nature $S$ into a set of outcomes $X$ that assign each state an outcome. To define the cumulative function, the outcomes of each prospect are arranged in an increasing order. A prospect $f$ is then represented as a sequence of pair $\left(x_{i}, A_{i}\right)$, which yields $x_{i}$ if $A_{i}$ occurs, where $x_{i}>x_{l}$ if $i>l$ and $A_{i}$ is a partition of $S$.

Positive subscripts, negative subscripts, and zero are used to denote positive outcomes, negative outcomes, and neutral outcome, respectively. The positive part of $f$, i.e. $f^{+}$, is obtained by letting $f^{+}(s)=f(s)$ if $f(s)>0$, otherwise $f^{+}(s)=0$. The negative part of $f$, i.e. $f^{-}$, is defined similarly. Cumulative prospect theory asserts that it exists a strictly increasing value function $v: X \rightarrow \Re$. Satisfying that $v\left(x_{0}\right)=v(0)=0$, and decision weights functions $w^{+}$and $w^{-}$, such that, for $f=\left(x_{i}, A_{i}\right)$, $-m \leq i \leq n$ (Tversky, Kahneman 1992; Avineri 2006).
Prospects are defined by the followings:

$$
\begin{aligned}
& V(f)=V\left(f^{+}\right)+V\left(f^{-}\right) \\
& V\left(f^{+}\right)=\sum_{i=0}^{n} \pi_{i}^{+}\left(f^{+}\right) \cdot v\left(x_{i}\right) \\
& V\left(f^{-}\right)=\sum_{i=-m}^{0} \pi_{i}^{-}\left(f^{-}\right) \cdot v\left(x_{i}\right),
\end{aligned}
$$

where: $V\left(f^{+}\right)$is the prospect gains values; $V\left(f^{-}\right)$is the prospect losses value; $\pi_{i}^{+}\left(f^{+}\right)=\left(\pi_{0}^{+}, \cdots, \pi_{n}^{+}\right)$are the decision weights of the gains; $\pi_{i}^{-}\left(f^{-}\right)=\left(\pi_{0}^{-}, \cdots, \pi_{n}^{-}\right)$are the decision weights of the losses (Tversky, Kahneman 1992; Avineri 2006).

If the prospect $f=\left(x_{i}, A_{i}\right)$ is given by a probability distribution $p\left(A_{i}\right)=p_{i}$, it can be viewed as a probabilistic or risky prospect $\left(x_{i}, p_{i}\right)$. In this case, decision weights are defined by the followings (Tversky, Kahneman 1992; Avineri 2006):

$$
\begin{aligned}
& \pi_{n}^{+}=w^{+}\left(p_{n}\right) ; \\
& \pi_{-m}^{-}=w^{-}\left(p_{-m}\right) ; \\
& \pi_{i}^{+}=w^{+}\left(p_{i}+\cdots+p_{n}\right)-w^{+}\left(p_{i+1}+\cdots+p_{n}\right) \\
& 0 \leq i \leq n-1 \\
& \pi_{i}^{-}=w^{-}\left(p_{-m}+\cdots+p_{i}\right)-w^{-}\left(p_{-m}+\cdots+p_{i-1}\right) \\
& 1-m \leq i \leq 0 .
\end{aligned}
$$

